\title{
Auxiliares de biblioteca e trabalho informacional: desafios e possibilidades para o Sibi/UFPA
}

\author{
Rubens da Silva Ferreira \\ M.Sc. em planejamento do desenvolvimento (Naea/UFPA), com área \\ de concentração em políticas públicas. \\ E-mail: rubenspa@yahoo.com
}

\begin{abstract}
Bibliotecários sem auxiliares capacitados são como médicos sem enfermeiros.
\end{abstract} (SILVA; ARAÚJO, 2003, p. 14)

\section{Resumo}

O objetivo deste relato é conhecer a rotina de trabalho dos auxiliares do Sistema de Bibliotecas da Universidade Federal do Pará (Sibi/UFPA), como trabalhadores que participam do trabalho informacional. Os dados foram obtidos a partir de questionários enviados a 26 unidades de informação da UFPA, selecionadas segundo uma amostragem por tipicidade. Os resultados mostram, entre outras questões, que auxiliares de biblioteca estão concentrados em tarefas próprias do serviço de empréstimo/devolução de publicações. No que se refere aos serviços auxiliares de preparação e conservação de material bibliográfico, verifica-se que eles têm sido apropriados pelos bibliotecários. A pesquisa aponta para a necessidade de uma política institucional de qualificação dos auxiliares de biblioteca para o trabalho informacional.

\section{Palavras-chave}

Auxiliares de biblioteca. Trabalho informacional. Sistemas de bibliotecas universitárias. Universidade Federal do Pará.

\section{Library assistants and information work: challenges and possibilities to the Sibi/UFPA}

\begin{abstract}
The study reported aimed to assess the daily routine of the work carried out by library assistants from the Library System of the Federal University of Para (Sibi/UFPA) as information workers. The data was collected via questionnaires sent to 26 libraries that have been selected according to a sample defined by type of university. The results showed that library assistants are concentrated in the loan service tasks. The auxiliary services of preparation and conservation of bibliographical materials are totally carried out by librarians. The research points to the need of an institutional policy regard the qualification of library assistants as information workers.
\end{abstract}

\section{Keyword}

Library assistants. Information work. Academic library systems. Federal University of Pará (Brazil).

\section{INTRODUÇÃO}

Debates acerca do perfil profissional do bibliotecário aparecem com destaque na literatura em biblioteconomia e ciência da informação a partir da segunda metade dos anos de 1900. Esta preocupação ajusta-se a um quadro mundial caracterizado por palavras como fluidez, mudança, instabilidade e flexibilidade, principalmente no que se refere ao mercado de trabalho. Novas proposições curriculares para as universidades, habilidades gerenciais, facilidade para o trabalho em grupo, postura empreendedora, conhecimentos sobre o uso de equipamentos eletrônicos e sobre negócios (SMIT, 2000; FERREIRA, 2003) surgem com regularidade nas discussões acadêmicas quanto ao tipo de profissional da informação com melhores possibilidades de trabalho.

Ainda que os bibliotecários sejam os pioneiros a trabalhar a informação de maneira sistemática, verifica-se, nos dias atuais, grande diversidade de profissionais convergindo para o mercado da informação. Neste ponto, Mostafa e Pacheco (1995, p. 175) constatam que esse mercado é composto por um mosaico de trabalhadores, sejam eles de nível médio ou superior, que desempenham tarefas às vezes similares àquelas desenvolvidas nas bibliotecas, nos arquivos ou nos centros de documentação, mas com metodologia própria. Por conseguinte, ao se pensar no profissional da informação como aquele formado apenas nas universidades, estará sendo excluída uma série de outros trabalhadores de nível médio, cujo aprendizado do trabalho informacional* se dá na realização cotidiana de certas tarefas, de um modo geral, orientadas por outro trabalhador com formação universitária.

\footnotetext{
* Entenda-se por trabalho informacional aquele cujas atividades estão concentradas no manejo da informação como matéria-prima a ser coletada, processada, armazenada, recuperada e disseminada (MIRANDA, 2004; DAVENPORT, 1998; PÁEZ URDANETA, 1992).
} 
Os auxiliares de biblioteca estão inscritos no quadro exposto anteriormente. Sem formação específica, esses trabalhadores estão diariamente a lidar com as demandas dos usuários* por informações, mais especificamente quando são designados para o serviço de referência. No que concerne aos demais serviços peculiares ao ambiente das bibliotecas, eles executam tarefas de apoio ao bibliotecário na aquisição e no processamento técnico, bem como na parte administrativa (CONSELHO FEDERAL DE BIBLIOTECONOMIA, 1973; SILVA; ARAÚJO, 2003). Quando lotados em unidades de informação de maior porte, com serviços distribuídos em setores, esses trabalhadores tendem a se especializar em determinadas tarefas. Porém, quando trabalham em bibliotecas menores, com um ou no máximo dois bibliotecários, passam a executar um número maior de atividades.

É nessa perspectiva que os auxiliares de biblioteca são tomados aqui como objeto de estudo. Tal interesse foi delineado a partir da constatação de que, na literatura em biblioteconomia e ciência da informação, os trabalhos acadêmicos sobre recursos humanos têm se concentrado apenas nas competências e na qualificação dos bibliotecários (SMIT, 2000; FERREIRA, 2003; CARVALHO, 2004), resultando, assim, na invisibilização dos auxiliares de biblioteca. Desse modo, adotando o Sistema de Bibliotecas da Universidade Federal do Pará (Sibi/UFPA) como referencial empírico, importa saber como os sujeitos em foco têm lidado com sua rotina de trabalho nas bibliotecas, a fim de identificar seus desafios e suas possibilidades no trabalho informacional.

\section{PERCURSO METODOLÓGICO}

Um primeiro momento do trabalho foi dedicado à realização do levantamento bibliográfico com o propósito de construir um corpo teórico que pudesse auxiliar a análise dos dados coletados. No segundo momento, para produzir um conhecimento sobre os auxiliares de biblioteca do Sibi/UFPA, a pesquisa concentrou-se em

\footnotetext{
* Silva e Araújo (2003, p. 103) fazem distinção entre clientela, leitores e usuários. Conforme essas autoras, a clientela consiste em um termo genérico que engloba toda a comunidade atendida por uma unidade de informação, fazendo parte dela tanto os leitores quanto os usuários. Os primeiros correspondem àqueles que recorrem à biblioteca como espaço de leitura, ou ainda, para fazer empréstimo de publicações que serão lidas mais tarde nas residências deles. O segundo termo aplicase aos indivíduos que utilizam vários serviços oferecidos pela biblioteca, tais como a comutação bibliográfica, a pesquisa em bases de dados, o acesso à Internet e até mesmo a leitura. Neste trabalho, porém, não serão consideradas tais distinções semânticas, preferindo desse modo o emprego do termo usuário, por ser mais amplamente falado pelos (as) bibliotecários (as) do Sibi/UFPA.
}

identificar o perfil socioprofissional desses trabalhadores e as atividades por eles desenvolvidas, verificando, também, as dificuldades enfrentadas no ambiente de trabalho como entrave à realização de um trabalho informacional de qualidade. Conduzida sob uma abordagem quali-quantitativa (MOSTAFA, 1983, apud OLIVEIRA, 2003, p. 59), a coleta de dados foi realizada por meio de questionários híbridos, enviados aos auxiliares de 26 das 32 bibliotecas setoriais do Sibi/UFPA. Destas, obteve-se o retorno de 11 unidades de informação, portanto, $42 \%$ da amostra, o que permite um grau confiável de generalização dos resultados.

Seguindo critérios para a seleção de uma amostragem por tipicidade (MARCONI; LAKATOS, 1992), seis unidades de informação foram excluídas da pesquisa. A biblioteca do Núcleo Pedagógico Integrado (NPI) não foi contemplada, por tratar-se de uma unidade de informação escolar, voltada para as necessidades do ensino fundamental e médio. Quanto à Biblioteca Central (BC), sua exclusão se deve à infra-estrutura tecnológica e ao grande quadro de bibliotecários que lá trabalham, contrastando com o reduzido número de profissionais existentes nas unidades setoriais que estão a executar inúmeras tarefas. Dada a inexistência de profissionais bibliotecários em alguns campi do interior do estado que pudessem fornecer dados sobre o trabalho desenvolvido pelos auxiliares, as unidades de informação de Soure (PA), Cametá (PA) e Breves (PA) não foram selecionadas. A biblioteca do campus de Bragança (PA) na qual o autor deste trabalho desenvolveu atividades de gestor à época da coleta de dados - também foi desconsiderada do estudo, a fim de garantir a imparcialidade na análise das evidências produzidas e agora socializadas neste artigo.

\section{PERSPECTIVAS TEÓRICAS}

As tarefas atribuídas aos auxiliares de bibliotecas são expressas em linhas gerais na Resolução n. 075/73 do CFB (CONSELHO FEDERAL DE BIBLIOTECONOMIA, 1973). Elas estão agrupadas em oito categorias: 1) serviços auxiliares de aquisição; 2) serviços técnicos auxiliares; 3) preparação e conservação do material bibliográfico; 4) serviços auxiliares de audiovisuais; 5) serviços auxiliares de consulta e empréstimo; 6) divulgação; 7) serviços auxiliares de processamento de dados; 8) outras tarefas de ordem administrativa. Somadas, essas categorias possuem 46 orientações quanto ao trabalho diário dos auxiliares de biblioteca, embora se encontrem desatualizadas ante as inovações tecnológicas já absorvidas pelas unidades de informação na atualidade, e antes inexistentes à época em que essa Resolução foi 
instituída. No entanto, acredita-se que elas não perderam o seu valor, sendo, ainda, importante referência quanto às tarefas que esses trabalhadores podem executar.

Embora os auxiliares de biblioteca participem do trabalho informacional, a literatura em biblioteconomia e ciência de informação apresenta contrapontos quanto a quem deve ser considerado profissional da informação. Em seu estudo sobre o "emergente mercado da informação", Mostafa e Pacheco (1995) verificam que há uma miríade de profissionais atuando no setor de serviços, mais especificamente na área de informação, independentemente de possuir formação superior em biblioteconomia. Por isso, a crítica que as autoras fazem às pesquisas sobre novos perfis para o mercado da informação refere-se à limitação nas abordagens utilizadas, pois, ao contemplarem somente o bibliotecário como profissional da informação, elas se revelam superficiais, protecionistas e corporativistas.

Ao incorrer neste erro apontado por Mostafa e Pacheco, essas pesquisas acabam por ocultar grande diversidade de postos de trabalho não-convencionais, ocupados por pessoal de nível médio e/ou superior que está a lidar fundamentalmente com a informação. Nessa mesma linha de pensamento, Straussman (1985), citado por Barbosa (1998, p. 53), define como profissional da informação todo o indivíduo que "trabalha com informação em vez de objetos”. Em outra perspectiva, Barbosa (1998) refuta concepções desse tipo, pois, para ele, apenas aquele que possui a informação como o "objeto central" do seu trabalho pode assumir tal status.

Contudo, defende-se aqui que as duas abordagens não se excluem mutuamente, uma vez que a polêmica pode ser operacionalmente revolvida ao menos no campo semântico. As divergências que surgem entre os teóricos sobre o assunto parecem residir no emprego do termo "profissional". Notadamente essa palavra comporta sentidos diversos, os quais só podem ser delimitados com base no contexto discursivo. Dentre os sentidos possíveis em que ela pode ser empregada no processo comunicativo, tem-se ofício e atividade/ocupação especializada (FERREIRA, 1999). O primeiro é de sentido genérico, podendo ser utilizado para designar qualquer atividade, ocupação ou trabalho que gere renda a quem o exerce. O segundo, como bem colocado por Meadows (1999), envolve a aquisição de um grau especializado de conhecimentos e a obediência a certos padrões técnicos de procedimento quanto ao saber fazer.

Por conseguinte, ainda que sem formação técnica/ científica, os auxiliares de biblioteca podem ser considerados profissionais da informação. Primeiro, porque eles se ajustam à abordagem de Straussman, pois o trabalho que realizam nas bibliotecas tem por base um conjunto de tarefas voltadas à seleção, à organização, à recuperação e à disseminação da informação, embora no nível de apoio ao que é desenvolvido tecnicamente, em profundidade, pelos profissionais bibliotecários. Em segundo lugar, como posto por Barbosa (1998), o trabalho que os auxiliares de biblioteca executam tem como eixo central a informação. Desse modo, as concepções de Straussman e de Barbosa quanto a quem deve ser considerado profissional da informação não são mutuamente excludentes, uma vez que dependem dos contextos em que são aplicadas. Ao que tudo indica, elas se mostram mais eficientes para definir os profissionais da informação quando usadas em conjunto, posto que tomadas isoladamente, revelam-se pouco consistentes. Assim, tal como evidenciado por Mostafa e Pacheco (1995), nem só de pessoal com formação técnica ou superior vive o mercado da informação, do qual participam os bibliotecários e os auxiliares de biblioteca, dentre tantos outros trabalhadores que se possa enumerar.

\section{AUXILIARES DE BIBLIOTECA E TRABALHO INFORMACIONAL NO SIBI/UFPA}

A primeira parte do questionário aplicado junto aos auxiliares do Sibi/UFPA destinou-se à obtenção dos dados socioprofissionais desses trabalhadores. No que se refere ao gênero, têm-se oito auxiliares do sexo masculino (42\%) e 11 do sexo feminino (58\%). Comparando ao que se verificou entre os gestores, o ambiente de trabalho nas bibliotecas é um espaço predominantemente feminino. Uma hipótese nesse sentido aponta para os detalhes e para a atenção exigida ao se trabalhar a informação, o que demanda a aplicação de normas próprias da representação temática e descritiva de documentos. De certa forma, há, no senso comum, a crença de que trabalhos minuciosos são mais adequados ao universo feminino. Contudo, ao contrário do que possa suscitar uma "guerra dos sexos", defende-se aqui a idéia de que pessoas de ambos os sexos estão em condições de igualdade para exercer o trabalho informacional. Assim, a tradição do uso de mão-de-obra feminina nas bibliotecas tem mais a ver com a cristalização de valores de uma sociedade machista do que com a capacidade humana propriamente dita para qualquer modalidade de trabalho*.

\footnotetext{
* De fato, são muitos os exemplos da imposição da divisão do trabalho baseado no critério sexual. $O$ magistério e a enfermagem - assim como a biblioteconomia - foram considerados por muito tempo como campos de atuação feminina, especialmente por demandarem habilidades que se contrapõem aos caracteres culturalmente atribuídos aos homens
} 
Quanto à idade dos auxiliares, destaca-se a presença de um grupo jovem de trabalhadores. Dos 19 respondentes, oito (42\%) estão concentrados na faixa dos 25 aos 35 anos de idade, o que denota a possibilidade de aprimoramento para o trabalho informacional; isto é, se investirem em cursos que estimulem o desenvolvimento de habilidades pertinentes às atividades exercidas nas bibliotecas do Sibi/ UFPA, precisamente aquelas que envolvem o uso de tecnologias de informação. Um segundo grupo de trabalhadores é formado por seis indivíduos, entre 36 e 46 anos de idade (32\%), seguido por cinco auxiliares com mais de 46 anos (26\%). Estes, por sua vez, possuem a experiência acumulada ao longo dos anos de trabalho em bibliotecas, chamada na academia de conhecimento tácito*.

Os dados reunidos sobre a formação escolar dos auxiliares são reveladores sobre o tipo de trabalhador que está atuando nas bibliotecas setoriais da UFPA, tal como mostra o gráfico 1. Dentre os indivíduos contatados, oito (42\%) possuem o segundo grau completo, portanto, em concordância com a definição do Conselho Federal de Biblioteconomia sobre esse trabalhador, encarregado de subsidiar as atividades técnicas que competem ao profissional bibliotecário. O questionário mostrou, também, a ocorrência de auxiliares com formação superior. Dos 19 respondentes, seis (32\%) estão concluindo cursos de graduação. Destes, somente cinco (26\%) informaram os cursos que estão freqüentando. São eles administração (1); pedagogia (1); matemática (1) e letras (2). Desse grupo, um auxiliar (5\%) não informou o curso superior no qual está matriculado.

Um aspecto importante quanto aos dados atribuídos aos trabalhadores mais jovens, na faixa dos 25 aos 35 anos de idade, que têm ingressado no quadro de pessoal da universidade mediante concurso público, refere-se à

(CALDAS, 1997; CIDADÃ, 2000; SOUSA, 2000). Nessa perspectiva, ocupações que exigem passividade, paciência e atenção são tidas como próprias das mulheres, contrapondo-se às que exigem inteligência, ação e agilidade, portanto, próprias dos homens. Entretanto, na contemporaneidade, essa cisão sexual vem gradativamente diminuindo no mercado de trabalho, haja vista crescente integração de pessoas de ambos os sexos nas mais diferentes profissões.

** Este conhecimento gerado a partir de experiências pessoais e de sistemas de idéias próprios é dotado de alto grau de subjetividade, sendo, por isso, difícil de ser transmitido. Porém, Silva (2004, p. 145) acredita que o conhecimento tácito pode ser socializado por meio do freqüente diálogo face a face, ou de técnicas como o brainstorming, a observação, a repetição orientada por um mestre e pelo trabalho em equipe, por exemplo. contribuição que podem dar ao bibliotecário, uma vez que possuem conhecimentos especializados adquiridos em cursos de graduação. Dessa forma, podem ajudar os bibliotecários na indexação de certos tipos de documentos, auxiliando na seleção de termos que melhor representem o conteúdo de um item bibliográfico ou nãobibliográfico, contribuir no desenvolvimento de produtos e serviços de informação especializados e, ainda, colaborar nas atividades de seleção e aquisição de informações.

Uma parte menor dos auxiliares já possui o curso de graduação concluído, correspondendo a três respondentes $(16 \%)$, respectivamente com formação em geologia, ciências contábeis e letras. A auxiliar graduada em geologia é a única pós-graduada, com especialização em geofísica. Desse grupo que teve acesso ao ensino superior, apenas um (5\%) não chegou a completar o curso de graduação. Um dado contraditório levantado sobre a formação educacional dos auxiliares refere-se à presença de um trabalhador $(5 \%)$ com o ensino fundamental completo, o que vai de encontro ao CFB, que define o auxiliar de biblioteca como "profissional de nível médio" (SILVA; ARAÚJO, 2003, p. 120). Todavia, não se está aqui a dizer que trabalhadores nessa situação não estejam em condições de realizar tarefas de modo eficiente, posto que, na abordagem pelas competências, além daquelas desenvolvidas nos contextos formais de ensino e de aprendizagem, existem aquelas inerentes ao próprio indivíduo (STROOBANTS, 1997; MIRANDA, 2004). Mas, partindo da compreensão de que as instituições nas quais o trabalho informacional envolve tarefas com certo nível de complexidade, como no caso das bibliotecas, 
particularmente naquelas de natureza universitária, quanto mais qualificados forem os trabalhadores, melhor poderão desempenhar esse trabalho.

No que concerne ao enquadramento funcional dos auxiliares contados no Sibi/UFPA, nem todos pertencem ao quadro de pessoal da universidade. Dos 19 respondentes, 11 (58\%) são servidores públicos federais pertencentes à UFPA, e apenas um (5\%) é cedido de outra instituição federal. Os demais (37\%) são oriundos de outras esferas da administração pública, sendo que um (5\%) dos auxiliares é servidor estadual cedido para a UFPA, e seis (32\%) são cedidos pelo município. A presença deste último grupo é mais comum nas cidades do interior para as quais a universidade se expandiu a partir da década de 1980 (UNIVERSIDADE FEDERAL DO PARÁ, 2003), como forma de desconcentrar o acesso ao ensino superior na capital.

Mas, a interiorização levou consigo o acesso ao ensino superior para além da capital, e a instalação das bibliotecas dos campi não foi acompanhada pela contratação de bibliotecários. Em decorrência disso, em cidades como Bragança (PA), Abaetetuba (PA), Marabá (PA), Soure (PA) e Cametá (PA), o desenvolvimento do trabalho informacional ficou a cargo de auxiliares de biblioteca, quadro que só mais recentemente tem sido alterado com a realização de concursos públicos para pessoal de nível superior. Em um esforço de conciliar a falta de profissionais bibliotecários, a Biblioteca Central - como unidade de informação coordenadora técnica do Sibi tem procurado orientar o trabalho dos auxiliares por meio de instruções técnicas, mais precisamente na forma de manuais.

Esses manuais foram elaborados no sentido de instruílos quanto às atividades mínimas que precisam desempenhar, particularmente aquelas referentes à seleção, à aquisição, à catalogação, à classificação, à organização dos materiais de informação e à circulação de publicações. Contudo, há de se considerar de capital importância a contratação de mais bibliotecários para o desenvolvimento das bibliotecas dos campi do interior que funcionam como simples salas de leitura, muito aquém, portanto, do que elas podem oferecer em termos de produtos e serviços de informação à sua comunidade acadêmica.

Em relação ao tempo de atuação como auxiliares de biblioteca, o conjunto dos trabalhadores apresenta-se de forma bem distribuída. Dos 19 respondentes, dois (11\%) são recém-concursados, possuindo menos de um ano de serviço na biblioteca na qual estão lotados, estando, portanto, em contato ainda inicial com o trabalho informacional. Um grupo de quatro auxiliares (21\%) exerce essa função em um período que varia de um a cinco anos. Outros quatro (21\%) participam do cotidiano do trabalho nas bibliotecas do Sibi/UFPA entre seis e dez anos de serviço. Por fim, um grupo maior composto de cinco indivíduos (26\%) está a realizar o trabalho informacional em um período de 11 a 15 anos.

De acordo com Stroobants (1997) e Miranda (2004), esse grupo de trabalhadores mais experiente pertence a uma categoria de indivíduos que já acumularam conhecimento significativo, não apenas sobre as atividades que executam, mas também sobre a rotina da organização a que servem. Nesse ponto, tal conhecimento pode ser útil na resolução dos problemas que eventualmente surgem no ambiente de trabalho, precisando, assim, ser mobilizado pela organização. Ou seja, no caso das bibliotecas do Sibi/UFPA, os gestores precisam estimular os auxiliares a compartilhar esse conhecimento via canais de comunicação acessíveis a eles, como, por exemplo, na forma de pequenas reuniões envolvendo a equipe da biblioteca. Nesta direção, os gestores não podem perder de vista que, ao lidar diretamente com os usuários, os auxiliares podem identificar aspectos que precisam ser melhorados nos produtos e nos serviços ofertados à comunidade acadêmica, propiciando o feedback necessário ao planejamento das atividades de uma unidade de informação.

Ainda que o tempo de serviço seja um fator importante para o desenvolvimento das competências do trabalhador, ele não é o suficiente. Enquanto uma parte das habilidades dos indivíduos para o trabalho resulta do contato contínuo com as tarefas atribuídas a eles, outra parte ocorre dentro dos contextos formais de ensino/ aprendizagem (STROOBANTS, 1997; MIRANDA, 2004). Por conseguinte, ao serem indagados sobre os cursos e/ou treinamentos feitos nos dois últimos anos, os auxiliares, de modo geral, mostraram iniciativa quanto à aquisição de conhecimentos que pudessem melhorar seu desempenho profissional.

Dada a disseminação das novas tecnologias de informação (NTI) no Sibi/UFPA, esses trabalhadores recorreram a diferentes cursos de informática. Entre os respondentes, dez (47\%) matricularam-se em cursos de Microsoft Word, uma vez que os computadores já substituem as máquinas de escrever nas quais os auxiliares passavam parte do seu tempo datilografando fichas catalográficas. Oito respondentes (42\%) disseram ter feito curso de Microsoft 
Excel; quatro (21\%) de Microsoft PowerPoint e um (5\%) de Microsoft Access. Porém, um leque diversificado de cursos e/ou de treinamentos foi procurado no sentido de melhorar o lado humano e profissional desses trabalhadores.

Considerando que os auxiliares se ocupam em boa parte da jornada de trabalho com o atendimento ao público, verificou-se que cinco (26\%) deles participaram de cursos de qualidade no atendimento ao cliente. Outros quatro (21\%) procuraram cursos de motivação, entrando em contato com teorias que explicam o comportamento humano orientado para a satisfação não apenas de suas necessidades econômicas e fisiológicas, mas também de auto-realização, de estima e de afeto (CHIAVENATO, 1993), que, se alcançadas, revertem-se em produtividade no trabalho. Um grupo menor formado por dois auxiliares (11\%) participou de cursos de marketing. Como o trabalho informacional envolve habilidades de escrita, três trabalhadores (16\%) freqüen-taram cursos de produção de texto e/ou de redação.

Dos respondentes contatados na pesquisa, seis (32\%) participaram de outros cursos e/ou treinamentos, além dos que foram discriminados no questionário. Dentre esses, foram informados os seguintes cursos e/ou treinamentos realizados no período de 2003 a 2005: informática na educação; pedagogia de projetos; treinamento para auxiliar de biblioteca; empreendedorismo; normalização de trabalhos acadêmicos; qualidade total no serviço público; ética nas organizações. Dos 19 auxiliares contatados, somente um (5\%) disse não ter procurado qualificação no período referido, o que permite concluir que a maioria dos auxiliares inscritos na amostragem da pesquisa está consciente da importância do aprendizado continuado. Outros três (16\%) preferiram não responder à pergunta.

A questão inicial do questionário tinha por objetivo saber se os auxiliares recebem o acompanhamento técnico dos bibliotecários, como profissionais da informação com nível superior, capacitados para instruí-los na realização do trabalho informacional no Sibi/UFPA. Entre os contatados, 16 (84\%) declararam trabalhar sob a orientação do bibliotecário. Apenas um (5\%) afirmou exercer suas atividades sem qualquer orientação técnica, o que demanda apuração no sentido de saber se tal orientação tem sido dispensada em função da experiência adquirida por esse auxiliar, por omissão do bibliotecário, ou, talvez, por questões relacionadas a um clima organizacional conflituoso. Dois trabalhadores (11\%), não responderam a essa pergunta.
Dentre as questões levantadas, procurou-se situar, também, quais as tarefas os auxiliares mais gostam de fazer no dia-a-dia das unidades de informação da UFPA. Os 19 respondentes (100\%) afirmaram gostar de trabalhar no serviço de referência, atendendo aos usuários. Outra tarefa que 12 (63\%) respondentes disseram gostar de realizar é a arrumação dos livros nas estantes e a devolução/empréstimo de materiais. Tarefas que envolvem a digitação de textos e pequenos reparos em materiais bibliográficos também aparecem dentre as preferidas de oito auxiliares (42\%). Segundo Silva e Araújo (2003), os auxiliares podem realizar pequenos reparos em publicações danificadas, desde que sejam preparados para isso. Nessa direção, a Biblioteca Central pode oferecer treinamentos curtos para os que desejam aprender técnicas emergenciais utilizadas para prolongar o tempo de vida útil dos documentos. Iniciativas nesse sentido são importantes para as bibliotecas setoriais, sobretudo para aquelas instaladas no interior, onde não há pessoal preparado para se dedicar a essa atividade.

O auxílio à preparação técnica de materiais bibliográficos e não-bibliográficos aparece indicado por cinco trabalhadores $(26 \%)$ como uma tarefa que agrada, seguida pelo recebimento/expedição de correspondência, citada por quatro respondentes (21\%). Quatro trabalhadores (21\%) informaram outros afazeres do interesse deles, tais como a realização de levantamentos bibliográficos e o treinamento de usuários na utilização de bases de dados, tarefas, aliás, que não aparecem enumeradas na Resolução n. 075/1973 do CFB e que demonstram que os auxiliares têm procurado diversificar o trabalho informacional.

Quanto aos serviços auxiliares de aquisição visualizados no gráfico 2, a seguir, dos 19 respondentes, 14 (75\%) disseram carimbar os documentos recém-adquiridos pela unidade de informação em que trabalham. Outros 13 auxiliares $(68 \%)$ conferem os materiais de informação adquiridos para verificar se correspondem de fato às especificações dos itens solicitados na compra. Oito trabalhadores (42\%) informaram que são encarregados de registrar os documentos que chegam à biblioteca por compra e/ou por doação, ao passo que 11 (58\%) não realizam essa tarefa. Todavia, somente quatro (21\%) registram as baixas sofridas no acervo.

Abrir os documentos adquiridos para conferir a paginação faz parte da rotina de trabalho de apenas quatro trabalhadores (16\%). Outras tarefas auxiliares na aquisição - como a verificação dos pedidos de compra e o arquivamento das faturas - são realizadas por dois auxiliares (11\%). Esse número é menor ainda no que diz 
respeito às tarefas de organização do catálogo de livreiros e à permuta de publicações, as quais estão a cargo de um único trabalhador, ou seja, são realizadas apenas por $5 \%$ da amostra. A baixa presença de auxiliares na atividade de aquisição evidencia que os bibliotecários têm assumido tal trabalho sozinhos, provavelmente em uma tentativa de reduzir a possibilidade de erros, o que, na pior das hipóteses, gera sobrecarga de trabalho para os gestores, à medida que se negam a delegar essas atividades àqueles que deveriam desempenhá-las.

\section{GRÁFICO 2}

\section{Tarefas realizadas pelos auxiliares do Sibi/UFPA na aquisição}

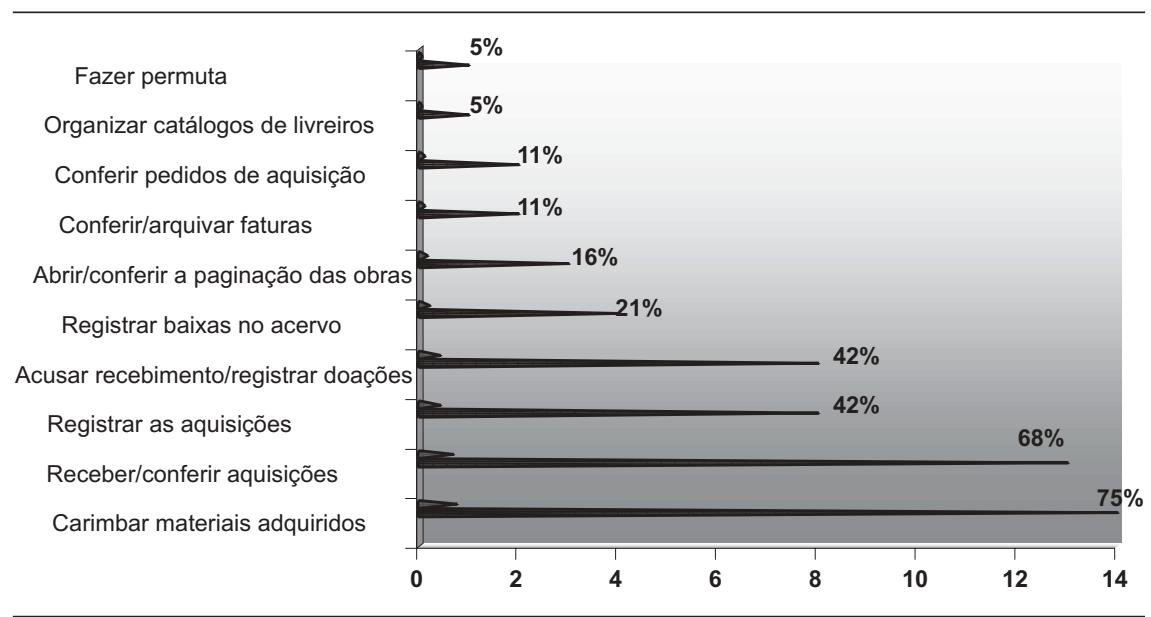

Indagados quanto à participação nos serviços auxiliares de processamento técnico, os trabalhadores em foco mostraram que a automação das bibliotecas do Sibi/UFPA acabou por aboli-los da tarefa de datilografar fichas catalográficas. Assim, dos 19 auxiliares contatados, 11 (58\%) não realizam mais esse trabalho. Dos oito trabalhadores que subsidiam os bibliotecários nessa atividade, três (16\%) ainda continuam a datilografar fichas catalográficas e cinco $(26 \%)$ as intercalam nos catálogos da biblioteca. Notadamente a expansão do software Pergamum para as demais unidades de informação do Sibi/UFPA irá suplantar em definitivo essas tarefas do cotidiano dos auxiliares de biblioteca. No entanto, Silva e Araújo (2003) sugerem que esses trabalhadores precisam aprender a extrair produtos dos sistemas informatizados, tais como relatórios e estatísticas de uso dos materiais de informação, como forma de dar suporte ao trabalho dos bibliotecários.

No que tange aos serviços auxiliares de preparação e conservação de materiais bibliográficos e nãobibliográficos, os auxiliares desempenham todas as tarefas previstas na Resolução n. 075/73 do CFB, seja em maior ou em menor número. Destarte, 13 trabalhadores (32\%) ainda preparam fichas de bolso para os documentos destinados ao empréstimo domiciliar. Dos 19 auxiliares, 11 (26\%) disseram fixar as etiquetas nas lombadas das publicações adquiridas pelas bibliotecas. Outros nove (21\%) realizam pequenos reparos nos materiais bibliográficos e não-bibliográficos danificados. A limpeza e a conservação dos itens constituintes do acervo é realizada por seis auxiliares $(32 \%)$, enquanto a preparação de documentos para encadernação faz parte da rotina de trabalho de três respondentes (16\%).
Os serviços auxiliares de audiovisuais que figuram na Resolução 075/73 do CFB são apontados na pesquisa como os menos comuns ao dia-a-dia dos auxiliares de biblioteca do Sibi/UFPA. Dessa maneira, somente cinco trabalhadores $(26 \%)$ realizam tarefas de conservação e arquivamento de materiais, tais como fitas de videocassete e discos de vídeo digital interativo (DVD), por exemplo. Essa baixa ocorrência pode ser atribuída, a título de hipótese, à rara presença de documentos audiovisuais no acervo das bibliotecas que integram o Sibi/UFPA, em contraste com um volume maior de documentos gráficos, principalmente de impressos, na forma de livros e de periódicos científicos.

Em contrapartida, a pesquisa revela que parte considerável do tempo de trabalho dos auxiliares está concentrada nos serviços de consulta e de empréstimo, como pode ser observado no gráfico 3. Entre as tarefas previstas nesses serviços, está o fornecimento de informações elementares aos usuários quanto ao expediente das bibliotecas e quanto às normas que regulam o funcionamento delas, conforme disciplina a Resolução nº 075/73 do CFB. Nesse ponto, 18 respondentes (95\%) afirmaram fornecer tais orientações ao público que atendem. Dos trabalhadores contatados, 17 (89\%) costumam explicar aos usuários como devem utilizar as obras de referência. As tarefas de empréstimo, renovação e devolução de publicações são realizadas por 15 (79\%) dos 19 auxiliares.

O controle de cadastro de usuários é uma tarefa que deve ser realizada pelos auxiliares de biblioteca, fazendo parte da rotina de trabalho de 14 respondentes (74\%). No que se refere ao empréstimo de publicações, as bibliotecas do Sibi/UFPA vivem realidades distintas. Em algumas delas, 
ele é automatizado; em outras, continua a ser operado manualmente. Assim, a organização do fichário de empréstimo continua a ser realizada por nove auxiliares $(47 \%)$. A estatística - que indica aspectos importantes a serem utilizados na avaliação dos serviços e dos produtos de informação de uma biblioteca (SILVA; ARAÚJO, 2003) é controlada por oito trabalhadores (42\%), número igual ao de auxiliares que organizam os salões de leitura dos locais em que estão lotados. No que se refere à reserva de publicações para empréstimo, somente sete respondentes (37\%) declararam realizá-la. Por fim, quatro auxiliares (21\%) informaram fazer o inventário anual do acervo, ajudando os bibliotecários a acompanhar o crescimento e as eventuais perdas nas coleções.

Quanto à participação dos auxiliares de bibliotecas do Sibi/UFPA em tarefas voltadas para a divulgação de atividades científicas e culturais, ou, ainda, dos produtos e dos serviços oferecidos aos usuários, verificou-se que ela é pequena. Dos 19 respondentes, 14 (73\%) informaram não realizar essas tarefas. Entre os cinco trabalhadores que as executam, três (16\%) disseram digitar listas com as aquisições recentes da biblioteca, ou digitar boletins informativos para distribuí-los à comunidade acadêmica. Dois (11\%) auxiliares declararam afixar cartazes ou outros documentos de divulgação científica e cultural.

Ao levar-se em consideração a baixa participação desses trabalhadores em tarefas de divulgação, pode-se pensar se as bibliotecas do Sibi/UFPA estão efetivamente realizando a disseminação da informação e, se estão, quem a realiza, já que os auxiliares não estão a executá-la como indicam os baixos números levantados na pesquisa. Notadamente esta é uma questão que merece estudos mais aprofundados, haja vista que, Silva e Araújo (2003), por meio de atividades de divulgação, a biblioteca pode colocar o usuário em contato com informações utilitárias, como as que tratam de minicursos, palestras, seminários, concursos e lançamentos de livros que eventualmente possam interessá-los.

Como a Resolução no 075/73 do CFB encontra-se desatualizada no que concerne aos serviços auxiliares de processamento de dados, não foram incluídas na pesquisa questões sobre esse aspecto*. Em contraparida, procurouse saber que outras tarefas os trabalhadores em foco realizam nas bibliotecas do Sibi/UFPA. Entre os 19 respondentes, apenas quatro (21\%) disseram organizar arquivos de correspondências, além de realizar o conjunto de tarefas até aqui analisado. Como se pode observar, embora os auxiliares participem do trabalho informacional nas bibliotecas do Sibi/UFPA, executando tarefas específicas no rol de atividades que competem a eles, parte desse trabalho tem sido possivelmente executada por outros trabalhadores, o que não se sabe precisar com exatidão se por bibliotecários, ou por bolsistas do curso de biblioteconomia.

As três últimas questões do questionário foram do tipo aberta, oferecendo aos auxiliares a possibilidade de expressar as dificuldades que enfrentam no cotidiano das suas unidades de informação, de recomendar melhorias nas condições de trabalho e, por fim, de manifestar se gostam ou não de trabalhar nas bibliotecas do Sibi/UFPA.

Com relação às dificuldades enfrentadas, os respondentes revelaram que a carência de computadores constitui um fator limitante ao desenvolvimento dos serviços nas bibliotecas, tal como se pode verificar nos depoimentos a seguir:

A principal dificuldade é o fato de ser um trabalho parcialmente manual, no sentido de não ser informatizado, desde a procura, o empréstimo, até a devolução do livro, o que requer mais tempo para

\footnotetext{
* Na Resolução no 075/73, as tarefas relacionadas aos serviços auxiliares de processamento de dados são as seguintes: (1) preparar material para perfuração de cartões; (2) operar a perfuração de cartões e equipamento correlato; (3) manter os arquivos pertinentes.
} 


\section{Rubens da Silva Ferreira}

isso, gerando dificuldades para a realização de outras tarefas que, às vezes, requerem soluções imediatas (auxiliar de biblioteca C)*

Os computadores lentos são um problema, pois, como trabalhamos em rede - e eu trabalho direto com pesquisa on-line -, necessitamos do uso contínuo da Internet. De vez em quando, temos problemas com o sistema (auxiliar de biblioteca J).

A minha maior dificuldade é quando preciso informar a alguém se existe ou não determinado livro no acervo da biblioteca. Acredito que um computador ajudaria bastante nesta tarefa, além de poder agilizar outros procedimentos que no momento são executados manualmente, como, por exemplo, a emissão de comprovante de devolução ao usuário (auxiliar de biblioteca P).

Como se vê, o elemento crítico em tais reclamações tem a ver com o tempo subutilizado em tarefas que dependem de equipamentos obsoletos, ou, na pior das hipóteses, na impossibilidade de realizá-las ante a falta de computadores. Como bem observaram os respondentes, a automação dos catálogos das bibliotecas e dos serviços de empréstimo e de devolução liberaria os auxiliares para realizar outras tarefas, otimizando o tempo no atendimento aos usuários.

Questões relacionadas ao comportamento dos usuários também são citadas como incômodas no cotidiano de trabalho dos auxiliares de biblioteca do Sibi/UFPA, embora não possam ser consideradas dificuldades propriamente ditas, mas parte de uma rotina de trabalho necessária. Nos discursos dos respondentes, elas emergem em tom de insatisfação ao descumprimento dos regulamentos e das normas das unidades de informação, ou como conseqüência do que os auxiliares acreditam ser uma espécie de "desconsideração" para com os trabalhos que realizam. Assim, dizem alguns que "é uma dificuldade conseguir que os alunos devolvam os livros nas datas acertadas e manter a biblioteca sempre limpa e arrumada" (auxiliar de biblioteca D), ou, ainda, "a falta de conscientização dos usuários no que diz respeito aos direitos e deveres é um dos problemas que enfrento" (auxiliar de biblioteca N). Ponto de vista similar também pode ser observado no discurso a seguir:

\footnotetext{
* A identidade dos respondentes foi preservada, de forma que, neste artigo, eles são indicados somente por sua ocupação, seguida de uma letra do alfabeto, de "A" a "S", atribuída por ordem de recebimento dos questionários.
}

Tenho dificuldades em manter as estantes sempre arrumadas, pois os usuários tiram os livros e não colocam no lugar. Também os livros geralmente são devolvidos fora do prazo, até mesmo os livros de consulta são levados com demora na devolução (auxiliar de biblioteca F).

Nos casos mencionados, há de se ressaltar que aquilo a que os auxiliares se referem como "dificuldades" enfrentadas no ambiente de trabalho são tarefas que, apesar de trabalhosas, precisam ser realizadas.

Certamente chega a causar desconforto verificar que todo o tempo despendido na arrumação dos livros nas estantes é desfeita em questão de segundos. Diante de situações desse tipo, é fundamental que os auxiliares entendam que organizar o acervo faz parte da rotina de trabalho em qualquer biblioteca, seja ela universitária ou não. Todavia, essa tarefa se torna mais simples em unidades de informação de pequeno porte, como as setoriais do Sibi/ UFPA, as quais não possuem acervo volumoso como o da Biblioteca Central, em Belém. O atraso na devolução das publicações ou o descumprimento às normas da biblioteca também não devem ser encarados por esses trabalhadores como dificuldades, posto que a isso se aplicam as sanções previstas nos regimentos das unidades de informação em que trabalham. A aplicação de sanções, como a suspensão dos usuários por atraso na devolução de materiais de informação, por exemplo, fica a cargo dos gestores, devendo os auxiliares apenas comunicá-los para que sejam tomadas as medidas que se fizerem necessárias.

Os auxiliares foram indagados quanto ao que poderia ser feito para melhorar o trabalho deles nas bibliotecas. Sendo a obsolescência e a insuficiência de computadores um problema comum a várias unidades constitutivas do Sibi/UFPA, não é de se estranhar que os trabalhadores reclamem pela aquisição desses equipamentos para a automação dos serviços e dos produtos oferecidos à comunidade acadêmica. Questões relacionadas à qualificação dos auxiliares também foram lembradas como aspecto importante para o melhor desempenho no trabalho informacional. Nessa direção, um deles declarou que os auxiliares de biblioteca precisam de "[...] qualificação humanística, uma vez que trabalham diretamente com o público. Daí ressalta-se a necessidade de cursos para o melhor atendimento aos usuários e ao público em geral" (auxiliar de biblioteca I).

A falta de recursos financeiros voltados para as necessidades das bibliotecas é apontada por alguns respondentes como algo que interfere diretamente no 
trabalho deles. Quando faltam materiais de consumo, as atividades são momentaneamente interrompidas, ou, como ocorre em alguns casos, os auxiliares e os gestores os compram com recursos próprios, em uma espécie de autofinanciamento do trabalho. Não obstante, um dos respondentes entende que, se houvesse verba destinada diretamente às bibliotecas setoriais, essas dificuldades seriam minimizadas. De fato, o que se verifica nos centros, nos núcleos e nos campi do interior é que as unidades de informação não são tidas como prioridades de investimento, o que resulta no sucateamento de parte delas. Até quando esta cultura de descaso com as bibliotecas irá persistir é algo difícil de prever, muito embora exista todo um discurso acadêmico contemporâneo reconhecendo a importância das bibliotecas universitárias na tal sociedade da informação.

Diante do que se quis conhecer sobre as dificuldades enfrentadas pelos auxiliares de biblioteca do Sibi/UFPA, considerou-se importante saber se eles gostam de trabalhar nessas unidades de informação. Este interesse resulta do entendimento de que trabalhar em um lugar com o qual se mantém uma relação dissonante é algo que afeta diretamente o rendimento e a qualidade do trabalho. Destarte, dos 19 respondentes, 18 (95\%) declararam gostar de trabalhar na biblioteca. Apenas um trabalhador não respondeu a essa pergunta.

Entre os que disseram gostar do que fazem, o contato com o público e com os livros são as razões que justificam essa afinidade, expressa, por exemplo, no fragmento discursivo abaixo:

Sim, gosto de trabalhar na biblioteca, principalmente com o público. Penso que todo trabalho tem seu mérito, desde que realizado com responsabilidade, compromisso, honestidade e dedicação. Além disso, existem as possibilidades de aprendizado, desde relações interpessoais até a aquisição [...] de conhecimento a partir do contato direto com as diversas obras. Há, ainda, algo que considero especial, que é poder contribuir para a difusão do conhecimento científico, pois é assim que me sinto ao servir a comunidade acadêmica e a sociedade em geral. Então, como não gostar de trabalhar na biblioteca? (auxiliar de biblioteca Q).

Apesar de o depoimento haver sido fornecido por trabalhadora recém-concursada, ele é representativo da função social do auxiliar de biblioteca no contexto da universidade. Por estarem mergulhados no trabalho informacional realizado dia após dia, esses trabalhadores não percebem que, por meio de cada tarefa executada, contribuem para o acesso ao conhecimento científico.

\section{DISCUSSÃO}

Embora a biblioteca seja representada pelo senso comum como um espaço que demanda pouco trabalho, um olhar mais sistemático sobre o cotidiano das unidades de informação revela grande diversidade de tarefas por serem realizadas diariamente. Os dados coletados acerca do trabalho informacional dos auxiliares de biblioteca do Sibi/UFPA são reveladores. É certo que as tarefas previstas na Resolução no 075/73 do CFB constituem apenas uma orientação quanto às funções básicas desses trabalhadores, já que podem executar muitas outras atividades para subsidiar os bibliotecários no trabalho de seleção, aquisição, processamento, armazenamento, recuperação e disseminação da informação.

No que tange à divisão do trabalho, a pesquisa aponta para a hipótese de que gestores têm tomado para si tarefas que deveriam ser realizadas pelos auxiliares, a exemplo do registro de materiais bibliográficos e nãobibliográficos, das baixas sofridas no acervo, da conferência dos materiais adquiridos e do arquivamento das faturas de compra de publicações. Nesse sentido, é compreensível que os bibliotecários exijam qualidade na realização das tarefas, haja vista que as informações processadas no trabalho informacional nas bibliotecas universitárias são direcionadas para as atividades de ensino, de pesquisa e de extensão. Porém, isso não significa dizer que os (as) bibliotecários (as) devam tomá-las para si, pois, aos gestores, cabe o papel de orientar os auxiliares na realização do trabalho informacional e acompanhar seu desempenho, o que corresponde, efetivamente, às funções administrativas de comando e de controle.

Assim, posturas descentralizadoras permitiriam, entre outras coisas, que os trabalhadores aprendessem a ter responsabilidades sobre os serviços atribuídos eles, além de liberar os bibliotecários para a realização de outras atividades. A cultura acadêmica dos bibliotecários, que os impele quase que opressivamente a se aterem às normas e às regras necessárias para trabalhar a informação, pode estar fazendo com que os gestores centralizem tarefas que deveriam ser delegadas aos auxiliares. Não é para menos que Hafter e Wolls (1998) constataram, em estudo realizado nas bibliotecas norteamericanas, que os bibliotecários têm se dedicado a afazeres próprios dos auxiliares de biblioteca. De acordo com esses autores, os gestores deveriam voltar sua atenção para atividades que exigem habilidades cognitivas mais complexas, ocupando-se, entre outras coisas, do 
planejamento organizacional, de atividades de pesquisa e information literacy*.

Além dos bibliotecários, bolsistas de biblioteconomia podem estar sendo utilizados para cumprir tarefas dos auxiliares, em função dos conhecimentos técnicos que adquirem na universidade. Neste ponto, importa lembrar que os estudantes não devem substituir os auxiliares de biblioteca no trabalho informacional, mas atuar juntamente com eles, como forma de complementar o aprendizado teórico adquirido em sala de aula. Práticas desse tipo podem estar ocorrendo também nas unidades do Sibi dos campi do interior, porém com bolsistas oriundos de outros cursos, como letras e pedagogia, uma vez que a graduação em biblioteconomia existe apenas no campus-sede da UFPA, em Belém. No entanto, a proposição sobre outros indivíduos estarem realizando tarefas que competem aos auxiliares de biblioteca só pode ser comprovada mediante estudo específico, o que não está ao alcance deste trabalho.

Em relação à qualificação profissional, a procura dos auxiliares de biblioteca por cursos e treinamentos indica que tais trabalhadores estão conscientes da importância da educação contínua para o aperfeiçoamento no trabalho informacional. $\mathrm{O}$ aprendizado no uso de softwares, o aprimoramento da capacidade de comunicação escrita e a busca de melhoria nas relações interpessoais são emblemáticos da atitude dos respondentes ante a necessidade de aprender sempre em tempos de uma sociedade da informação (MIRANDA, 2004; DUDZIAK, 2003; CASTELLS, 1999; HAFTER; WOLLS, 1998). Considerando que somente um auxiliar não procurou nenhum curso e/ou treinamento nos dois últimos anos, acredita-se que o Sibi/UFPA dispõe, em seu conjunto, de um montante de conhecimentos sobre o trabalho informacional que precisa ser compartilhado permanentemente entre o pessoal das bibliotecas que compõem o sistema, como forma de melhorar os serviços e os produtos desenvolvidos para a comunidade acadêmica.

Ao se levar em conta que os auxiliares só passam a conhecer o trabalho informacional a partir da experiência

\footnotetext{
* Surgida nos anos de 1970, a expressão information literacy ainda possui sentido controverso, tal como analisado por Dudziak (2003). Todavia, Hatschbach (2002, p. 49) conclui, em dissertação de mestrado, que, em português, information literacy pode ser traduzido como "competência em informação". Assim, profissionais como os bibliotecários, nessa perspectiva, têm um papel importante na information literacy, ao contribuírem em programas educativos voltados para o desenvolvimento das habilidades necessárias ao trabalho informacional. Daí a responsabilidade dos gestores das bibliotecas na preparação dos auxiliares para as atividades que devem realizar.
}

diária nas bibliotecas, o contato com os gestores é imprescindível para o desenvolvimento das competências desses trabalhadores. As próprias tarefas previstas na Resolução nº 075/73 do CFB implicam o compartilhamento dos saberes técnicos dos bibliotecários com a equipe de trabalho que coordenam. Assim, noções de catalogação, classificação, desenvolvimento de coleção, restauração, alfabetação e estatística, por exemplo, constituem parte desse saber que precisa ser socializado para que os auxiliares de biblioteca tenham condições de participar do trabalho informacional minimamente instrumentalizados.

Em contrapartida, a pesquisa revelou que os auxiliares também possuem conhecimentos para compartilhar com os gestores do Sibi/UFPA. Enquanto os trabalhadores de nível médio dispõem de informações sobre a satisfação dos usuários em relação aos serviços e aos produtos oferecidos pela biblioteca, os que estão cursando a graduação ou que já são egressos de cursos superiores representam um capital intelectual com muitas possibilidades para o trabalho informacional. Como identificado a partir da coleta de dados, auxiliares com formação acadêmica em geologia, letras, pedagogia e ciências contábeis podem, juntamente com os gestores, realizar estudos por demandas específicas de informação e, a partir disso, desenvolver produtos e serviços especializados para a comunidade acadêmica da UFPA.

Ademais, envolver os auxiliares de biblioteca em atividades voltadas para o trabalho informacional dentro dos seus respectivos campos de atuação pode vir a ser algo estimulante e motivador, no sentido de inquietálos a buscar soluções para as lacunas de informação nas suas respectivas profissões. Neste mister, a sinergia entre bibliotecários e auxiliares no intercambiamento de conhecimentos técnicos especializados acaba por transformar-se em fator de inovação no trabalho informacional. Porém, ações nessa direção só podem consolidar-se em realidade, se a equipe da biblioteca estiver disposta a mobilizar energia e assumir responsabilidades para a criação de novos produtos e serviços de informação, o que de outra forma se torna inviável.

Um aspecto limitador apontado pelos auxiliares quanto ao cotidiano nas bibliotecas do Sibi/UFPA refere-se à obsolescência tecnológica e à falta de recursos computacionais para a realização de algumas tarefas próprias do trabalho informacional. Tal como relatado, serviços como o de empréstimo e de devolução oneram o tempo dos auxiliares e dos usuários quando feitos manualmente, o que ainda é uma realidade em 20 (68\%) 
das 32 bibliotecas do Sibi/UFPA (MOREIRA, 2005). Entretanto, como alerta Davenport (1998), é inútil pensar que a tecnologia irá resolver, por si só, todos os problemas das organizações, sejam elas comerciais, socais ou educacionais, como no caso das bibliotecas universitárias. Aplicar tecnologia na rotina de trabalho sem reeducar os auxiliares para que controlem os erros que eventualmente ocorrem resulta, igualmente, em desperdício de tempo, uma vez que se torna mais desgastante corrigir as falhas do que evitá-las com a atenção necessária que o trabalho informacional requer.

Em que pesem todos os esforços de estímulo à participação em cursos e/ou treinamentos, a utilização de manuais e a orientação técnica, outro ponto crítico para o melhor desempenho do trabalho informacional, podem residir no componente psicológico do trabalhador. Assim, a otimização de uma rotina de trabalho pode encontrar resistências no ambiente das bibliotecas, sobretudo quando as mudanças implicarem novas tarefas para os auxiliares, portanto novas responsabilidades a serem assumidas pela equipe. Questões dessa ordem, ao que tudo indica, parecem não se aplicar no caso do pessoal contatado na pesquisa, posto que 16 (84\%) dos 19 trabalhadores disseram ter feito algum curso ou treinamento nos dois últimos anos. Tal evidência está a indicar, assim, o interesse dos auxiliares pela aquisição de conhecimentos que os torne mais bem capacitados para o trabalho informacional. E essa capacitação se torna essencial, ao considerar-se seu ambiente acadêmico, no qual a comunidade de usuários atendida pelas bibliotecas do Sibi/UFPA depende, fundamentalmente, do acesso a informações de natureza técnica e científica, seja para a formação profissional dos discentes, seja para as atividades de pesquisa que se revertem em benefício da sociedade maior.

\section{CONSIDERAÇÕES FINAIS}

Embora a Resolução n 075/73 do CFB esteja desatualizada em alguns aspectos da rotina de trabalho própria dos auxiliares de biblioteca, depois de 32 anos em vigor, ela continua a ser um referencial importante. A pesquisa revela que, no Sibi/UFPA, os auxiliares têm se ocupado predominantemente do serviço de referência, ao passo que tarefas de apoio ao processamento técnico de documentos têm sido dominadas pelos bibliotecários, talvez por força da forte tradição tecnicista da profissão. De todo modo, entende-se que tais trabalhadores precisam desenvolver habilidades para além do mero trabalho rotineiro, a fim de poder participar juntamente com os bibliotecários no planejamento, na implementação e na avaliação de novos produtos e serviços de informação.

Preparar os auxiliares para um ambiente informacional dinâmico, voltado para as necessidades da comunidade atendida pela Universidade Federal do Pará, implica uma política de capacitação que melhore as habilidades desses trabalhadores. Essa política precisa levar em conta aspectos que contribuam para a melhoria no atendimento aos usuários, tais como a capacidade de comunicação oral e escrita, o aprendizado no uso de recursos computacionais e o desenvolvimento de uma postura empreendedora para lidar com as dificuldades próprias do cotidiano das bibliotecas, tais como a falta de recursos financeiros e materiais. Nesse ponto, o próprio capital intelectual da instituição pode ser mobilizado para a oferta de cursos, palestras e oficinas que se apliquem ao trabalho informacional. Bibliotecários do Sibi e professores dos cursos de letras, administração, biblioteconomia, psicologia e ciências da computação possuem conhecimentos especializados que muito podem contribuir para a qualificação dos auxiliares de biblioteca.

O estímulo à qualificação dos auxiliares de biblioteca, porém, não pode limitar-se aos que estão lotados nas unidades do Sibi instaladas na capital paraense. No interior, precisamente nas cidades de Abaetetuba, Altamira, Bragança, Breves, Cametá, Marabá, Santarém e Soure, as oportunidades de aprendizado para o trabalho informacional são consideravelmente limitadas, assim como o acesso à informação também se dá em um contexto marcado por dificuldades diversas para as populações locais. Não é para menos que, nessas localidades, as unidades do Sibi/UFPA acabem por desempenhar a função de bibliotecas públicas, haja vista que dispõem de acervos relativamente atualizados. Percebe-se, por conseguinte, o desafio que os trabalhadores dessas cidades têm em relação ao seu aperfeiçoamento na oferta de serviços e produtos direcionados para um público acadêmico, que precisa de informações técnicas e/ou científicas para a realização das atividades de ensino, de pesquisa e de extensão.

Em que pese a necessidade de qualificar os auxiliares de biblioteca para ajudar os bibliotecários na seleção, na aquisição, no processamento, no armazenamento, na recuperação e na disseminação da informação para estudantes, professores/pesquisadores, técnicos e pessoal administrativo, só o tempo irá revelar a postura a ser tomada pela administração da universidade, qual seja de omissão, de desestímulo ou de apoio. Mas, enquanto tal posição não é definida, esse grupo de trabalhadores segue 
sua rotina, adquirindo conhecimentos sobre o trabalho informacional com a ajuda dos bibliotecários e com base nos erros e acertos vivenciados no dia-a-dia das bibliotecas. E para falar de um aspecto positivo identificado na pesquisa, as dificuldades enfrentadas nas unidades do Sibi parecem ser amenizadas pelo fato de os auxiliares perceberem que estão ajudando os usuários ao intermediá-los no acesso à informação, evidenciando, assim, uma consciência humanística da contribuição social do trabalho que realizam nas bibliotecas da UFPA.

\section{AGRADECIMENTOS}

Este trabalho é dedicado às auxiliares Lourdes Araújo e Graciethe Pinto, com quem convivi quando de minha breve estada na chefia da Biblioteca Professor Armando Bordallo da Silva (Campus UFPA Bragança, Pará), no período de maio de 2004 a maio de 2006. De fato, essas trabalhadoras foram a inspiração para a pesquisa que resultou no trabalho monográfico apresentado em dezembro de 2005 ao Curso de Especialização em Biblioteca Universitária (CSE/UFPA), orientado pela professora doutora Odaisa Oliveira e, agora, socializado neste artigo.

Artigo submetido em 19/11/2005 e aceito em 10/07/2006.

\section{REFERÊNCIAS}

BARBOSA, R. R. Perspectivas profissionais e educacionais em biblioteconomia e ciência da informação. Ciência da Informação, Brasília, v. 27, n. 1, p. 53-60, jan./abr. 1998.

CALDAS, I. G. Cidadania e política de gênero: ação reivindicatória das mulheres operárias em Manaus. In: ÁLVAREZ, M. L. M.; SANTOS, E. F. dos; D'INCAO, M. Â. (Org.). Mulher e modernidade na Amazônia. Belém: Cejup, 1997. p. 329-345. Tomo I.

CARVAlHO, I. C. L. As bibliotecas universitárias no Brasil. In: A socialização do conhecimento no espaço das bibliotecas universitárias. Niterói: Interciência, 2004. p. 82-95.

CASTELLS, M. Prólogo: a rede e o ser. In:

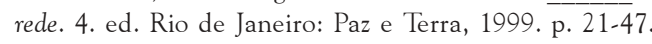

. A sociedade em

CHIAVENATO. Introdução à teoria geral da administração. 4. ed. São Paulo: Makron Books, 1993.

CIDADÃ de 2a classe: longe da igualdade de direitos, brasileiras sofrem discriminação. Problemas brasileiros, São Paulo, n. 141, p. 4-8, set./out. 2000.

CONSELHO FEDERAL DE BIBLIOTECONOMIA. Resolução CFB n. 75, de 28 de abril de 1973. Disponível em: < http://www.cfb.org.br/ legislacao/resolucoes/print/res075-73.htm >. Acesso: 03 ago. 2004.

DAVENPORT, T. H. Ecologia da informação: por que só a tecnologia não basta para o sucesso na era da informação. São Paulo: Futura, 1998.
DUDZIAK, E. A. Information literacy: princípios, filosofia e prática. Ciência da Informação, Brasília, v. 32, n. 1, p. 23-35, jan./abr. 2003.

FERREIRA, A. B. de H. Novo Aurélio século XXI: o dicionário da língua portuguesa. 3. ed. rev. e ampl. Rio de Janeiro: Nova Fronteira, 1999. p. 1436.

FERREIRA, D. T. Profissional da informação: perfil de habilidades demandadas pelo mercado de trabalho. Ciência da Informação, Brasília, v. 32, n. 1, p. 42-49, jan/abr. 2003.

HAFTER, R.; WOLLS, B. CE curricula: surveys produce more questions than answers. In: INTERNATIONAL FEDERATION OF LIBRARY ASSOCIATIONS AND INSTITUTIONS. General Conference, 64., 1998, Amsterdan. Electronic Proceedings... Amsterdan: IFLA. 1998. Disponível em: < http://www.ifla.org/IV/ifla64/057136e.htm >. Acesso em: 12 out. 2005.

HATSCHBACH, M. H. de L. Information literacy: aspectos conceituais e iniciativas em ambiente digital para o estudante de nível superior. 2002. 108 f. Dissertação (Mestrado em Ciência da Informação)Universidade Federal do Rio de Janeiro, Instituto Brasileiro de Informação em Ciência e Tecnologia, Rio de Janeiro, 2002.

MARCONI, M. de A.; LAKATOS, E. M. Técnicas de pesquisa: planejamento e execução de pesquisas, amostragem e técnicas de pesquisa, elaboração, análise e interpretação de dados. 2. ed. rev. e ampl. São Paulo: Atlas, 1992.

MEADOWS, A. J. Mudança e crescimento. In: científica. Brasília, DF: Briquet de Lemos, 1999. p. 2-38.

A comunicação

MIRANDA, S. V. Identificando competências informacionais. Ciência da Informação, Brasília, v. 33, n. 2, p. 112-122, maio/ago. 2004.

MOREIRA, S. M. B. L. Bibliotecas automatizadas do SIBI [mensagem pessoal]. Mensagem recebida por<rsf@ufpa.br> em 7 nov. 2005.

MOSTAFA, S. P.; PACHECO, M. O mercado emergente de informação. Ciência da Informação, Brasília, v. 24, n. 2, p. 171-180, maio/ago. 2003.

OLIVEIRA, E. F. T. de. Revendo o debate quantidade-qualidade: tendências da pesquisa na Biblioteconomia e Ciência da Informação. Transinformação, Campinas, v. 15, n. 1, p. 53-62, jan./abr. 2003.

PÁEZ URDANETA, I. O trabalho informacional na perspectiva do aprendizado tecnológico para o desenvolvimento. Ciência da Informação, Brasília, v. 21, n. 1, p. 115-127, maio/ago. 1992.

SILVA, D. A. da; ARAUJO, I. Auxiliar de bibliotecas: técnicas e práticas para formação profissional. 4. ed. rev. e aum. Brasília: Thesaurus, 2003.

SILVA, S. L. da. Gestão do conhecimento: uma visão crítica orientada pela abordagem da criação do conhecimento. Ciência da Informação, Brasília, v. 33, n. 2, p. 143-151, maio/ago. 2004.

SMIT, J. O profissional da informação e sua relação com as áreas de Biblioteconomia/Documentação, Arquivologia e Museologia. In: (Org.). Profissionais da informação: formação, perfil e atuação profissional. São Paulo: Polis, 2000. p. 119-134. (Coleção Palavrachave, 11).

SOUSA, G. T. de. Trabalho docente: questão de gênero. 2000. 50 f. Monografia (Licenciatura Plena em Pedagogia)- Universidade Federal do Pará, Bragança, 2000.

STROOBANTS, M. A visibilidade das competências. In: REPÉ, F; TANGUY, L. (Org.). Saberes e competências: o uso de tais noções na escola e na empresa. 2. ed. Campinas: Papirus, 1997. p. 135-166.

UNIVERSIDADE FEDERAL DO PARÁ. Pró-Reitoria de Planejamento e Desenvolvimento. Plano de desenvolvimento da Universidade Federal do Pará, 2001-2010. Belém, 2003. 